\title{
GMDH algorithm for modeling the outlet temperatures of a solar chimney based on the ambient temperature
}

\author{
Alibakhsh Kasaeian $^{1}$, Mehran Ghalamchi ${ }^{1}$, Mohammad Hossein Ahmadi ${ }^{1, a}$ \\ AND Mehrdad Ghalamchi ${ }^{2}$ \\ 1 Department of Renewable Energies, Faculty of New Science and Technologies, University of Tehran, Tehran, Iran \\ 2 Department of Energy Engineering, Graduate School of the Environment and Energy, Science and Research Branch, \\ Islamic Azad University, Tehran, Iran
}

Received 26 January 2016, Accepted 3 June 2016

\begin{abstract}
This work was carried out based on a constructed solar chimney with $2 \mathrm{~m}$ height and $3 \mathrm{~m}$ diameter. The temperature distributions were assessed based on the practical climatic conditions. In this work, the experimental data of temperature were investigated by a group method of data handling (GMDH). This method was applied as an artificial intelligence approach to predict the temperature changes, and also to find out the quality of the experimental data and temperature. In this case, a data set of 2000 conditionparameters for 30 days operation of solar chimney was applied. In order to obtain the network input and output variables, eight and four temperature sensors were set, respectively. In this study, according to the value correlation coefficient $\left(R^{2}\right)$ and the root-mean square error (RMSE), the results of the trained networks have been reported. In the modeling and calculations, the ambient temperatures have been considered. Also temperature prediction was carried out with high accuracy. Finally, the results showed that the solar chimney's experimental data were qualified with no noise and some formulas were obtained for each output based on the temperature input variables.
\end{abstract}

Key words: Solar chimney / temperature prediction / ambient temperature / GMDH method / neural network

\section{Introduction}

Renewable energy technologies are the clean sources of energy that have a much lower environmental impact than conventional energy technologies. Among the renewable sources, solar energy has a special situation in aspects of accessibility and diversity. Solar chimney is one of the most popular types of energy production means in the solar energy conversion area. The overall performance of solar chimney is described by some works which presented results for a prototype power plant built in Manzanares, Spain in 1982 [1-3]. Gannon and Von Backström [4] presented an analytical model for a single rotor layout for a large-scale solar chimney. The results show that the inlet guide vanes improve the performance. Also in another study [5] various radial sections were analyzed along the blades in the turbine model.

\footnotetext{
${ }^{a}$ Corresponding author:

mohammadhosein.ahmadi@gmail.com
}

Bernardes et al. [6] proposed a thermal and technical analysis for solar chimney power system. Bilgen and Rheault [7] designed a solar chimney system for power production at high latitudes and investigated its performance. The results showed solar chimney power plants at high latitudes produce as much as $85 \%$ of the same plants in the southern locations. Pretorius and Kröger [8] evaluated the influence of convective heat transfer governing equations of solar chimney. Also that research aimed at appraising the effectiveness of different kinds of soil and quality of collector roof glass on the performance of a conventional solar chimney power plant.

Koonsrisuk and Chitsomboon [9] worked on dimensional analysis of solar chimney power plant and proposed dimensionless variables with computational fluid dynamics (CFD) method to compare the experimental study of flow in a small-scale solar chimney and in another research [10], they combined eight primitive variables to reach only one dimensionless variable. Zhou et al. [11] constructed a small research pilot in which the temperature 


\section{Nomenclature}

\begin{tabular}{|ll|}
\hline$c_{p}$ & Specific heat capacity $\left(\mathrm{J} \cdot \mathrm{kg}^{-1} \cdot \mathrm{K}^{-1}\right)$ \\
$h$ & Convective heat transfer coefficient $\left(\mathrm{W} \cdot \mathrm{m}^{-2} \cdot \mathrm{K}^{-1}\right)$ \\
$\dot{m}$ & Mass flow rate $\left(\mathrm{kg} \cdot \mathrm{s}^{-1}\right)$ \\
$P$ & Pressure (bar) \\
$T$ & Temperature $(\mathrm{K})$ \\
$V$ & Quantity of velocity vector $\left(\mathrm{m} \cdot \mathrm{s}^{-1}\right)$ \\
$\rho$ & Density $\left(\mathrm{kg} \cdot \mathrm{m}^{-3}\right)$ \\
$\eta$ & Efficiency \\
$\dot{Q}$ & Heat flow $(\mathrm{kW})$ \\
$g$ & Gravitational acceleration $\left(\mathrm{m}^{-} \mathrm{s}^{-2}\right)$ \\
$H$ & Chimney height $(\mathrm{m})$ \\
$Z$ & Height (m) \\
$q$ & Heat flux (W.m $\left.{ }^{-2}\right)$ \\
$D$ & Diameter (m) \\
$A$ & Area of surface $\left(\mathrm{m}^{2}\right)$ \\
$r$ & Collector radius $(\mathrm{m})$ \\
$f$ & Friction coefficien \\
$L$ & Length (m) \\
\hline & $\quad$ Subscripts \\
\hline a & Ambient \\
$\mathrm{A}$ & Absorber \\
co & Collector \\
ch & Chimney \\
$\mathrm{t}$ & Turbine \\
\hline
\end{tabular}

difference between collector outlet and ambient reached to $24.1{ }^{\circ} \mathrm{C}$. Their results showed air temperature inversion appears in the chimney after sunrise both on a cool day and on a warm day.

Cost models for large-scale solar chimney power plants were evaluated by Fluri et al. [12]. Thermodynamic modeling of solar chimney power plant is studied by Petela [13], which was accompanied with evaluating energy and exergy balances. The optimal chimney height for maximum power output was analyzed by Zhou et al. [14] and their results were validated with the measurements of the prototype in Manzanares. Koonsrisuk et al. [15] described the constructed-theory for the geometry of solar chimney. Their results include an estimate of the height/radius ratio, maximum power and maximum mass flow rate. Bernardes and Backstrom [16] carried out some numerical simulations to study the performance of solar chimney. They evaluated the flow volume and the turbine pressure drop in their model. Their results showed the optimum ratio is not constant during the whole day and it is dependent on the heat transfer coefficients applied to the collector. Chergui et al. [17] analyzed a natural laminar convective heat transfer problem in a solar chimney. Their analysis included the heat transfer process and the fluid flow in the collector and chimney.

$\mathrm{Xu}$ et al. [18] carried out numerical simulations on air flow, heat transfer and power output characteristics of the solar chimney power plant. This model included energy storage layer and turbine which was similar to the Manzanares prototype. They also proposed mathemati- cal model of flow and heat transfer for the solar chimney power plant system. A new design of solar chimneydriven solar crop dryer (CDSCD) was presented by Afriyie et al. [19]. In another study [20], they developed mathematical models and a computer code to simulate the ventilation related to the design of the CDSCD.

Cao et al. [21] designed a sloped solar chimney power plant, consisted of an air collector $607.2 \mathrm{~m}$ diameter and $252.2 \mathrm{~m}$ chimney height. Their model was designed to produce $5 \mathrm{MW}$ electric power on a monthly average and after that Koonsrisuk [22] presented mathematical modeling of sloped solar chimney power plants. Cao et al. [23] compared the performance of a conventional solar chimney power plant and sloped solar chimney based on a heat transfer model. Zuo et al. [24] presented a new solar chimney power system consisting sea water desalination that had two usages, the production of electricity and fresh water. An exhaustive theoretical model for the performance evaluation of a solar chimney power plant was proposed by Li et al. [25] and the results were verified by the experimental data of the Manzanares pilot. They also evaluated the effects of chimney height and collector radius on the power output of a solar chimney. Hamdan [26] presented a mathematical thermal model for steady state airflow inside a solar chimney power plant based on Bernoulli equation with buoyancy effect and ideal gas equation. That study showed that the optimum turbine head plays the most important role in productivity.

Several studies have been done in GMDH method and neural network for engineering fields. System identification techniques are utilized in various fields to model and predict the behaviors of unknown and complex systems based on given input-output data [29]. For this purpose, soft computing methods, which involve computation in an imprecise environment, have attracted considerable attention of researchers. The components of fuzzy logic, neural network and evolutionary algorithms have great capability in solving complicated non-linear system identification and control problems [30].

Many analytical studies have been expended to use evolutionary methods as applicable tools for system identification [31-33]. Among these methods, the group method of data handling (GMDH) algorithm is a selforganizing approach which is generated based on the evaluation of their performances on a set of multi-input and single output data pairs $(X i, Y i)(i=1,2, \ldots, M)$. The GMDH was introduced by Ivakhnenko [34] as a multivariate analysis method for complicated systems modeling and identification. In this way, the GMDH can be applied to model complex systems without having specific knowledge of the systems.

The GMDH works by creating an analytical function in a feed forward network based on a quadratic node transfer function in which coefficients are obtained by regression technique [35]. Actually, the real GMDH algorithm in which the model coefficients are approximated by means of the least square method has been categorized as complete induction and incomplete induction, which 
represent the combinatorial (COMBI) and multi-layered iterative algorithms (MIA), respectively [36].

Recently, many researches were carried out based on stochastic search algorithms such as evolutionary methods. In those studies, evolutionary methods were beneficial dealing with complex problems and were utilized to design artificial neural networks. So the use of such selforganizing networks has result in successful application of the GMDH type algorithm in an extensive range of engineering, science and economics [37-43]. A comprehensive review of utilizing evolutionary algorithms in the design of artificial neural networks is presented in [44]. In recent years, genetic algorithms have been employed in a feed forward GMDH type neural network for each neuron searching its optimal set of connection with the preceding layer [45].

In this study, GMDH method as great optimizing algorithm is suggested to forecast the output temperatures of the solar chimney and implemented to decide on the initial weights of the factors employed in neural network. In current work, 2000 pattern numbers, which have been gained from experimental device, are used for both training the polynomial neural network according to $R^{2}$ and RMSE and prediction output data

\section{Theoretical analysis}

\subsection{Mathematical model of the solar chimney}

To determine the mathematical model of the solar chimney, the governing equations for the movement of air within the chimney and collector were considered separately. The analysis of the solar chimney power plant is based on a mathematical model developed by Schlaich et al. and Munson [3,26-28]. A schematic diagram of the solar chimney power plant is shown in Figure 1. Only the "simple" theoretical models are used to describe the entire power plant including the three major components, which are the solar collector, the chimney, and the wind turbine.

Air is heated by solar radiation under a circular roof open at the periphery. Since hot air is less dense than cold air, it rises up the chimney and is driven by the buoyancy effect due to the vertical column of hot air. The fluid is assumed as an ideal gas and the air movement inside a chimney is supposed to be a frictionless adiabatic process [26]. The system of the equations for an one dimensional steady compressible flow in a vertical chimney is expressed as followings:

$$
\begin{aligned}
\frac{P_{3}-P_{4}}{g \rho_{4}}=\left(z_{4}-z_{1}\right)_{\text {Gravity Head }}+\frac{\dot{m}^{2}}{2 g\left(A_{\mathrm{ch}} \rho_{4}\right)^{2}} \\
\times\left(f \frac{L}{D_{\mathrm{ch}}}+K_{\text {in }}+K_{\text {out }}\right)_{\text {Friction Head }}
\end{aligned}
$$

It is assumed that the distance between the ground and the collector roof is considered large enough to disregard the pressure drop in the collector section. So across the

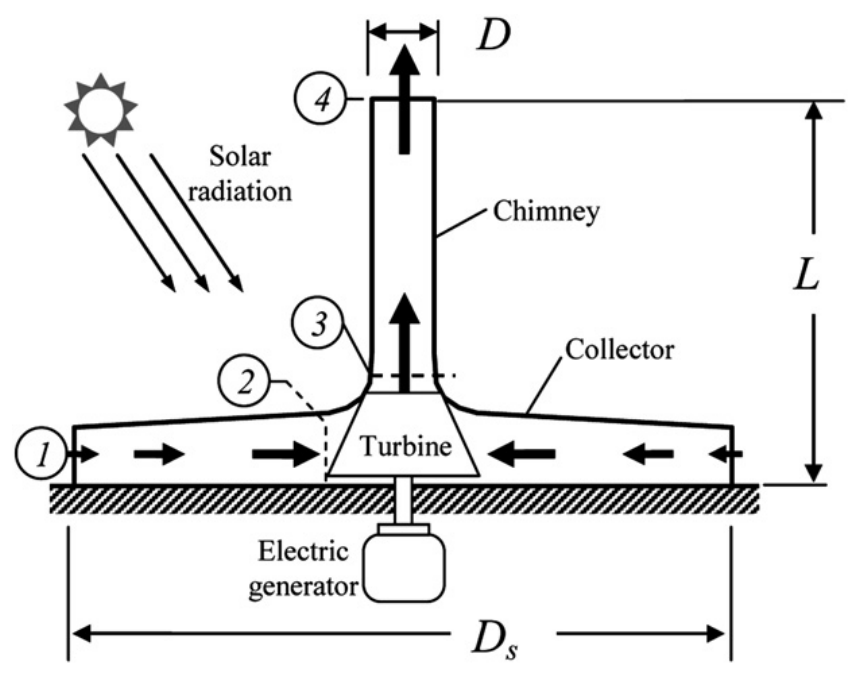

Fig. 1. Schematic layout of a conventional solar chimney power plant.

collector pressure drop is neglected; therefore the pressure at point 1 is equal to the pressure at point 2 . So the mass flow rate inside the solar chimney can be given by:

$$
\dot{m}=\rho_{3} V_{3} A_{\mathrm{ch}}
$$

According to reference [27], by balancing the kinetic and potential energies of the flow, the speed of fluid at the inlet of chimney can be expressed as:

$$
V_{3}=\left(2 g h_{\mathrm{ch}} \frac{\Delta T}{T_{a}}\right)
$$

An additional formula for the mass flow rate inside the solar chimney using energy equation for the collector section is:

$$
\dot{m}=\frac{q^{\prime \prime} A_{\text {coll }}}{h_{2}-h_{1}}
$$

where $q^{\prime \prime}$ is the heat flux and represents the absorbed solar radiation excluding the thermal losses. The main unknown in above equations is $h_{2}$. Because the surface area of the collector is much larger than the surface area of the chimney, it is assumed the heat radiated to the chimney is ignored. Therefore there is only a little temperature change across the chimney which is expressed as Equation (5).

$$
T_{3}=T_{4}
$$

Entropy across the turbine is taken constant, hence the pressure expansion is assumed to be reversible and adiabatic; therefore the entropy in point 3 is equal to the entropy in point 2 . The pressure head is related to turbine head which is given by:

$$
P_{3}=P_{2}-\rho_{2} g H_{\mathrm{t}}
$$

\subsection{Theoretical modeling of GMDH type of Artificial Neural Network}

The group method of data handling (GMDH) is a category of inductive algorithms for computer-based 
mathematical modeling of multi-parametric datasets that features parametric optimization of models. The method is a set of neurons in which various pairs of them in each layer are connected through a quadratic polynomial, therefore, generate new neurons in the next layer. This expression may be used in modeling to map inputs to outputs. In fact, the formal definition includes a function $\hat{f}$ in order to predict the output $\hat{y}$ for a specified input vector $X=\left(x_{1}, x_{2}, x_{3}, \ldots, x_{n}\right) . f$ and $y$ are the actual input and output which are defined as followings:

$$
\begin{aligned}
& y_{i}=f\left(x_{i 1}, x_{i 2}, x_{i 3}, \ldots, x_{\text {in }}\right)(i=1,2,3, \ldots, M) \\
& \hat{y}_{i}=\hat{f}\left(x_{i 1}, x_{i 2}, x_{i 3}, \ldots, x_{\text {in }}\right)(i=1,2,3, \ldots, M)
\end{aligned}
$$

Then, a GMDH type neural network must be applied in order to minimize the square of difference between the actual output and the predicted one:

$$
\sum_{i=1}^{M}\left[\hat{f}\left(x_{i 1}, x_{i 2}, x_{i 3}, \ldots, x_{\mathrm{in}}\right)-\hat{y}_{i}\right]^{2} \rightarrow \min
$$

The connection between the input and output variables can be expressed by a Kolmogorov-Gabor polynomial [34, 36-38]:

$$
\begin{gathered}
y=a_{0}+\sum_{i=1}^{n} a_{i} x_{i}+\sum_{i=1}^{n} \sum_{j=1}^{n} a_{i j} x_{i} x_{j} \\
+\sum_{i=1}^{n} \sum_{j=1}^{n} \sum_{k=1}^{n} a_{i j k} x_{i} x_{j} x_{k}+\ldots \\
\hat{y}=G\left(x_{i}, x_{j}\right)=a_{0}+a_{1} x_{i}+a_{2} x_{j}+a_{3} x_{i}^{2}+a_{4} x_{j}^{2}+a_{5} x_{i} x_{j}
\end{gathered}
$$

In order to minimize the difference between the actual output, $y$, and the calculated one, $\hat{y}$ for each pair of $x_{i}, x_{j}$ as input variables, the coefficients $a_{i}$ in Equation (11) are calculated by regression techniques.

In fact, a tree of polynomials is built using the quadratic form provided in Equation (11) whose coefficients are calculated in a least-squares sense. In this regard, the coefficients of each quadratic function $G_{i}$ are obtained to optimally fit the output in the whole set of input-output data pair, as follows:

$$
E=\frac{\sum_{i}^{M}\left(y_{i}-G_{i}\right)^{2}}{M} \rightarrow \min
$$

Simply, in the GMDH algorithm, all the possibilities of two independent variables out of total $n$ input variables are selected in order to construct the regression polynomial in the form of Equation (11) that best fits the dependent observations $\left(y_{i}, i=1,2, \ldots, M\right)$ in a least-squares sense.

Actually, $\left(\begin{array}{l}n \\ 2\end{array}\right)=\frac{n(n-1)}{2}$ neurons will be consequently built up in the first hidden layer of the feed forward network from the observations $\left\{\left(y_{i}, x_{i p}, x_{i q}\right) ;(i=1,2, \ldots, M\}\right.$ for different $p, q \in$

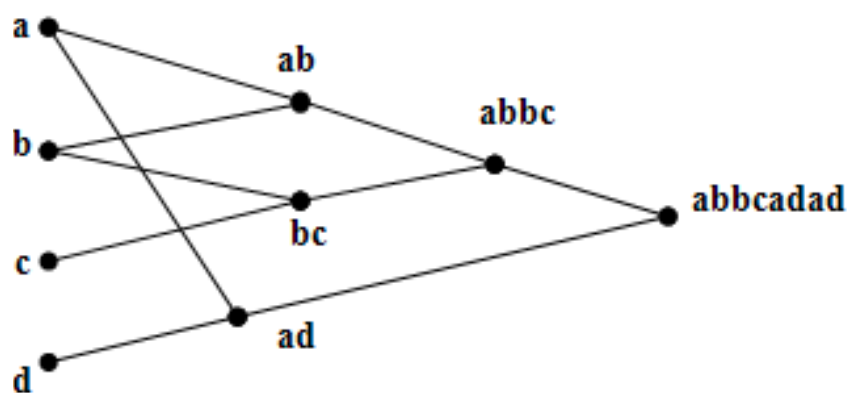

Fig. 2. A generalized GMDH network structure of chromosome.

$\{1,2, \ldots, n\}$. In other words, it is now possible to construct $M$ data triples $\left\{\left(y_{i}, x_{i p}, x_{i q}\right) ;(i=1,2, \ldots, M\}\right.$ from the observation using such $p, q \in\{1,2, \ldots, n\}$ in the form of

$$
\left[\begin{array}{lll}
x_{1 p} & x_{1 q} & y_{1} \\
x_{2 p} & x_{2 q} & y_{2} \\
x_{3 p} & x_{3 q} & y_{M}
\end{array}\right]
$$

Using the quadratic sub-expression in the form of Equation (11) for each row of $M$ data triples, the following matrix equation can be readily obtained as

$$
\begin{aligned}
A a & =Y \\
a & =\left\{a_{0}, a_{1}, a_{2}, a_{3}, a_{4}, a_{5}\right\} \\
Y & =\left\{y_{1}, y_{2}, y_{3}, \ldots, y_{M}\right\}^{T}
\end{aligned}
$$

where $a$ is the vector of unknown coefficients for the quadratic polynomial in Equation (11), and $Y$ is the vector of output values from observation. $A$ is given by:

$$
A=\left[\begin{array}{cccccc}
1 & x_{1 p} & x_{1 q} & x_{1 p} x_{1 q} & x_{1 p}^{2} & x_{1 q}^{2} \\
1 & x_{2 p} & x_{2 q} & x_{2 p} x_{2 q} & x_{2 p}^{2} & x_{2 q}^{2} \\
1 & x_{M p} & x_{M q} & x_{M p} x_{M q} & x_{M p}^{2} & x_{M q}^{2}
\end{array}\right]
$$

The least-squares technique from multiple-regression result is expressed as:

$$
a=\left(A^{T} A\right)^{-1} A^{T}
$$

Point to note that this procedure for each neuron of the next hidden layer is iterated and neurons in each layer are only connected to the neuron in its adjoining layer. Such a solution from normal equations is directly rather susceptible to round off errors [44-49].

Taking this advantage, it was possible to perform a simple encoding scheme for the genotype of each individual in the population as already proposed by [42-45]. The encoding schemes are shown in Figure 2.

According to Figure 2, output neuron (abbcadad) includes twice ad because the neuron (ad) at the first layer is connected to the output layer by directly going through the second layer. This procedure occurs when a neuron passes some adjoining hidden layers and connects to another neuron in the next following hidden layer. In this method scheme, the number of repetitions of neuron was given by $2^{\tilde{n}}$ where $\tilde{n}$ is the number of the passed hidden layers. The natural roulette wheel selection method 
is applied to choose two parents for producing two offspring's [42-45].

Combining of genetic algorithm with the GMDH type neural networks is started with representing each network as a string of the concatenated sub-strings of alphabetical digits. The fitness, $\varphi$, of each entire string of symbolic digits which represents a GMDH type neural network model is evaluated as followings [50-52]:

$$
\phi=\frac{1}{E}
$$

where $E$ is the mean square of error which is minimized within the evolutionary process by maximizing the fitness, $\varphi$. In this step, GMDH type neural network methods are produced by progressively increasing fitness, $\varphi$, until no further substantial progress is possible.

These statistical fields are based on RMSE as the rootmean squared error, $R^{2}$ as the absolute fraction of variance, and MAPE as the mean absolute percentage of error which are given by [50-52]:

$$
\begin{aligned}
R^{2} & =1-\left[\frac{\sum_{i=0}^{M}\left(Y_{i(\text { model })}-Y_{i(\text { Actual })}\right)^{2}}{\sum_{i=1}^{M}\left(Y_{i(\text { Actual })}\right)^{2}}\right] \\
R M S E & =\left[\frac{\sum_{i=0}^{M}\left(Y_{i(\text { model })}-Y_{i(\text { Actual })}\right)^{2}}{M}\right]^{1 / 2} \\
M A P E & =\left[\frac{\left.\sum_{i=0}^{M} \mid Y_{i(\text { model })}-Y_{i(\text { Actual })}\right)}{M \sum_{i=1}^{M}\left(Y_{i(\text { Actual })}\right)}\right]
\end{aligned}
$$

\section{Results and discussion}

An experimental solar chimney pilot consisted of an air collector $3 \mathrm{~m}$ in diameter and chimney height of $2 \mathrm{~m}$ was constructed at University of Tehran, Iran. The temperature distribution in the solar chimney setup was measured by 12 SMT160 sensors and recorded on data-logger setup. Eight of these sensors were utilized as the inputs of the system and four sensors as the outputs. The arrangement of the sensors is shown in Figure 3. As it is observed, six sensors are located on the absorbers, four ones are embedded for temperature measuring of the fluid and one sensor is put at the inlet of the chimney. $T_{1}^{\prime}$ to $T_{8}^{\prime}$ indicate the system inputs while $T_{1}$ to $T_{4}$ represent the system outputs.

The GMDH-type neural networks have been used to find the input-output relationship in the form of polynomial models. Such neural network identification process needs, in turn, some optimization methods to find the best network architecture. With this regard, GAs are organized in a new approach to design the whole architecture of the GMDH-type neural networks, i.e., the number of neurons in each hidden layer and their connectivity configuration combined with Singular Value Decomposition (SVD). This combination is applied to discover the optimal coefficients of quadratic expressions for modeling and prediction of the output temperatures based on the input data of the constructed solar chimney.

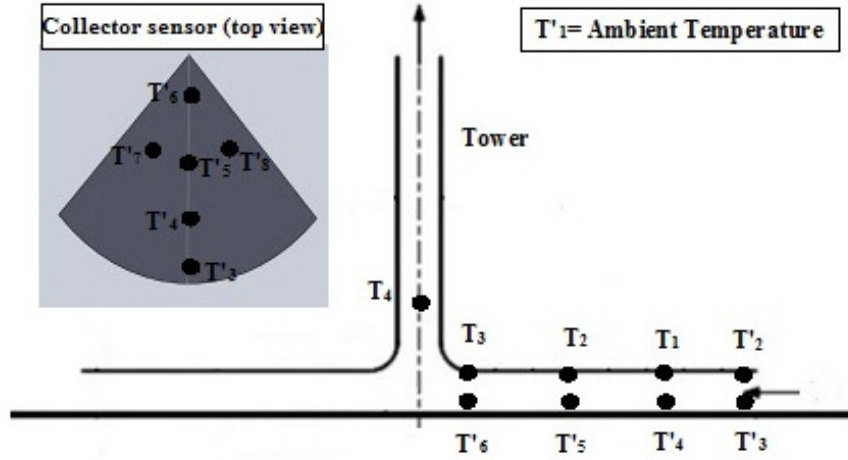

Fig. 3. Sensor arrangement of the absorber and fluid.

Table 1. Amount of the absolute fraction of variance, the root-mean squared error and the mean absolute percentage for $T_{1}$ model.

\begin{tabular}{cc}
\hline$R^{2}$ & 0.9906 \\
\hline MAPE & 0.00000915 \\
RMSE & 0.8027 \\
\hline
\end{tabular}

Table 2. Amount of the absolute fraction of variance, the root-mean squared error and the mean absolute percentage for $T_{2}$ model.

\begin{tabular}{cc}
\hline$R^{2}$ & 0.9875 \\
\hline MAPE & 0.00001032 \\
RMSE & 0.9268 \\
\hline
\end{tabular}

Table 3. Amount of the absolute fraction of variance, the root-mean squared error and the mean absolute percentage for $T_{3}$ model.

\begin{tabular}{cc}
\hline$R^{2}$ & 0.9822 \\
\hline MAPE & 0.00001240 \\
RMSE & 1.0664 \\
\hline
\end{tabular}

Table 4. Amount of the absolute fraction of variance, the root-mean squared error and the mean absolute percentage for $T_{4}$ model.

\begin{tabular}{cc}
\hline$R^{2}$ & 0.983 \\
\hline MAPE & 0.00001096 \\
RMSE & 0.9728 \\
\hline
\end{tabular}

Some statistical measures for $T_{1}, T_{2}, T_{3}$ and $T_{4}$ are given in Tables $1-4$, respectively. The correlation coefficient is high in all sections and this is shown that accuracy of the trained networks is appreciate.

The corresponding polynomial representation of such a model for $T_{1}$ is as followings:

$$
\text { See equation (22) next page. }
$$

The corresponding polynomial representation of such a model for $T_{2}$ is presented as:

$$
\text { See equation (23) next page. }
$$

The corresponding polynomial representation of such a model for $T_{3}$ is read as:

\section{See equation (24) next page.}




$$
\begin{aligned}
T_{1} & =0.649482+N 76 \times 1.18442-N 76 \times N 48 \times 0.0213749-N 48 \times 0.225523+N 48^{2} \times 0.0219758 \\
N 48 & =-13.4559-2.00866 \times T_{3}^{\prime}+T_{3}^{\prime} \times N 115 \times 0.272208-\left(T_{3}^{\prime}\right)^{2} \times 0.0875282+N 115 \times 4.15735-N 115^{2} \times 0.209706 \\
N 76 & =-20.1938+T_{2}^{\prime} \times 3.02076+T_{2}^{\prime} \times T_{6}^{\prime} \times 0.0736612-\left(T_{2}^{\prime}\right)^{2} \times 0.0893313-T_{6}^{\prime} \times 0.56505-\left(T_{6}^{\prime}\right)^{2} \times 0.0129832 \\
N 115 & =2.82216-T_{1}^{\prime} \times 0.390159+T_{1}^{\prime} \times T_{7}^{\prime} \times 0.0203775-\left(T_{1}^{\prime}\right)^{2} \times 0.00689403+T_{7}^{\prime} \times 1.23392-\left(T_{7}^{\prime}\right)^{2} \times 0.0158294
\end{aligned}
$$

$$
\begin{aligned}
T_{2} & =0.268754+N 46 \times 0.281634+N 46 \times N 60 \times 0.00839465+N 60 \times 0.699729-N 60^{2} \times 0.00809195 \\
N 46 & =-3.71305+N 90 \times 3.13447+N 90 \times N 121 \times 0.0646854-N 90^{2} \times 0.0673995-N 121 \times 1.92171 \\
N 60 & =-4.88004+N 86 \times 0.317896+N 86 \times N 106 \times 0.0506992-N 86^{2} \times 0.0207954+N 106 \times 0.959815-N 106^{2} \times 0.0335401 \\
N 86 & =-42.2945+T_{2}^{\prime} \times 6.27282+T_{2}^{\prime} \times T_{6}^{\prime} \times 0.13522-\left(T_{2}^{\prime}\right)^{2} \times 0.186239-T_{6}^{\prime} \times 1.80287-\left(T_{6}^{\prime}\right)^{2} \times 0.0202776 \\
N 90 & =-0.484459+T_{4}^{\prime} \times 1.42028+T_{4}^{\prime} \times T_{7}^{\prime} \times 0.225981-\left(T_{4}^{\prime}\right)^{2} \times 0.13289-T_{7}^{\prime} \times 0.282354-\left(T_{7}^{\prime}\right)^{2} \times 0.100004 \\
N 106 & =-25.4119-T_{1}^{\prime} \times 1.12963+T_{1}^{\prime} \times T_{2}^{\prime} \times 0.0629554-\left(T_{1}^{\prime}\right)^{2} \times 0.00194151+T_{2}^{\prime} \times 3.87368-\left(T_{2}^{\prime}\right)^{2} \times 0.0907913 \\
N 121 & =22.4997-T_{3}^{\prime} \times 1.50276-T_{3}^{\prime} \times T_{8}^{\prime} \times 0.166964+\left(T_{3}^{\prime}\right)^{2} \times 0.118525+T_{8}^{\prime} \times 1.25398+\left(T_{8}^{\prime}\right)^{2} \times 0.0626675
\end{aligned}
$$

$$
\begin{aligned}
T_{3} & =-2.06804+N 92 \times 2.21536+N 92 \times N 39 \times 0.199213-N 92^{2} \times 0.139326-N 39 \times 1.08793-N 39^{2} \times 0.0617369 \\
N 39 & =-0.688241+N 70 \times 0.583494-N 70^{2} \times 0.000499522+N 74 \times 0.454862 \\
N 70 & =-26.2777+T_{2}^{\prime} \times 3.76542+T_{2}^{\prime} \times T_{3}^{\prime} \times 0.0751355-\left(T_{2}^{\prime}\right)^{2} \times 0.103888-T_{3}^{\prime} \times 0.732453-\left(T_{3}^{\prime}\right)^{2} \times 0.0113413 \\
N 74 & =-1.62996+T_{2}^{\prime} \times 2.08367+T_{2}^{\prime} \times T_{6}^{\prime} \times 0.0796999-\left(T_{2}^{\prime}\right)^{2} \times 0.0761524-T_{6}^{\prime} \times 0.7946-\left(T_{6}^{\prime}\right)^{2} \times 0.0130868 \\
N 92 & =-42.6409+T_{2}^{\prime} \times 5.33236+T_{2}^{\prime} \times T_{4}^{\prime} \times 0.0773835-\left(T_{2}^{\prime}\right)^{2} \times 0.133506-T_{4}^{\prime} \times 1.01139-\left(T_{4}^{\prime}\right)^{2} * 0.00974921
\end{aligned}
$$

Finally, the corresponding polynomial representation of such a model for $T_{4}$ is stated as:

\section{See equation (25) next page.}

As it is shown in Figure 4, the trained network is an acceptable network based on GMDH algorithm with $R^{2}$ equal to 0.9906. Figure 5 shows the deviation of GMDH based on network outputs from experimental data which is acceptable 10 percent of experimental data. Figure 6 shows that all data are of high quality and have very low deviation. Also this figure shows excellent agreement between the achieved experimental data for $T_{1}$ and the GMDH algorithm outputs

Comparison of the GMDH-based trained network data for $T_{2}$ and the $T_{2}$ experimental data is shown in Figure 7. According to Figure 7, the trained networks based on GMDH have $R^{2}$ equal to 0.9875 , and this indicates that the networks have been trained from high quality experimental data of $T_{2}$. A high agreement between the GMDH output data and the experimental data of $\mathrm{T}_{2}$ is shown in Figure 8. Figure 9 shows the deviation of GMDH based on the network results obtained of the experimental data. As it is evident, due to the high quality of the data, there are deviations between $-10 \%$ to $+10 \%$ which is perfectly acceptable.

In Figure 10, the output of the trained network based on GMDH for $T_{3}$ shows that $R^{2}$ is 0.9822 . Also Figure 11 shows the GMDH output data and the experimental data

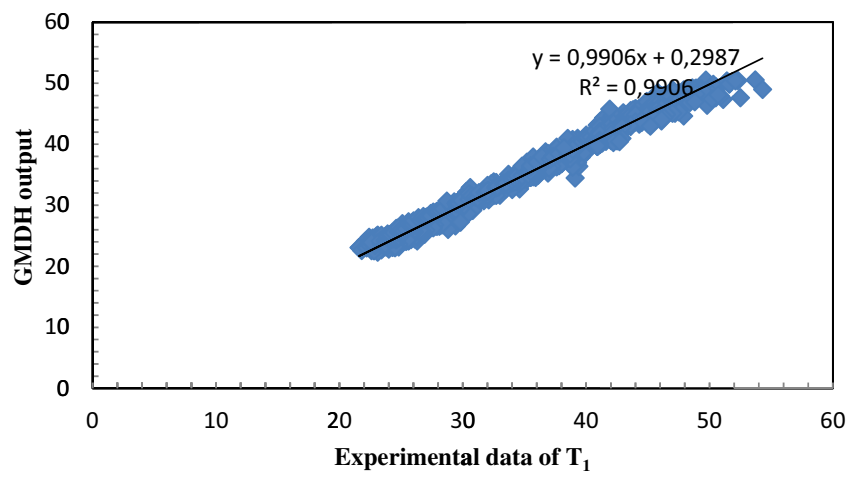

Fig. 4. Regression plot of the outputs of the developed model versus the relevant experimental $T_{1}$ data.

of $T_{3}$. The deviation of GMDH output data from experimental data of $T_{3}$ is shown in Figure 12.

Figure 13 shows the quality of the trained network based on GMDH algorithm for $T_{4}$ with $R^{2}$ equal to 0.983 . The deviation of GMDH output data from experimental data of $T_{4}$ is shown in Figure 14. In Figure 15, the comparison between the predicted data by GMDH algorithm for $T_{4}$ and the $T_{4}$ experimental data is shown and a good agreement is observed. 


$$
\begin{aligned}
T_{4} & =-0.966397-N 51 \times 2.53989-N 51 \times N 56 \times 1.2516+N 51^{2} \times 0.677946+N 56 \times 3.59487+N 56^{2} \times 0.57285 \\
N 51 & =-2.57827+T_{2}^{\prime} \times 0.963425+T_{2}^{\prime} \times N 88 \times 0.0643538-\left(T_{2}^{\prime}\right)^{2} \times 0.0499402+N 88 \times 0.218621-N 88^{2} \times 0.0175173 \\
N 56 & =-5.29847-N 96 \times 1.19457+N 96^{2} \times 0.0295196+N 107 \times 2.51684-N 107^{2} \times 0.0341741 \\
N 88 & =-12.1064+T_{4}^{\prime} \times 0.724768+T_{4}^{\prime} \times T_{6}^{\prime} \times 0.032138-\left(T_{4}^{\prime}\right) \wedge 2 \times 0.0220724+T_{6}^{\prime} \times 0.984032-\left(T_{6}^{\prime}\right)^{2} \times 0.0225059 \\
N 96 & =-7.10383+T_{2}^{\prime} \times 0.156967+T_{2}^{\prime} \times T_{6}^{\prime} \times 0.0229241-\left(T_{2}^{\prime}\right)^{2} \times 0.0152894+T_{6}^{\prime} \times 1.28414-\left(T_{6}^{\prime}\right)^{2} \times 0.0164269 \\
N 107 & =-10.8151+T_{7}^{\prime} \times 0.286465+T_{7}^{\prime} \times T_{8}^{\prime} \times 0.0384885-\left(T_{7}^{\prime}\right)^{2} \times 0.0190191+T_{8}^{\prime} \times 1.36042-\left(T_{8}^{\prime}\right)^{2} \times 0.031975
\end{aligned}
$$

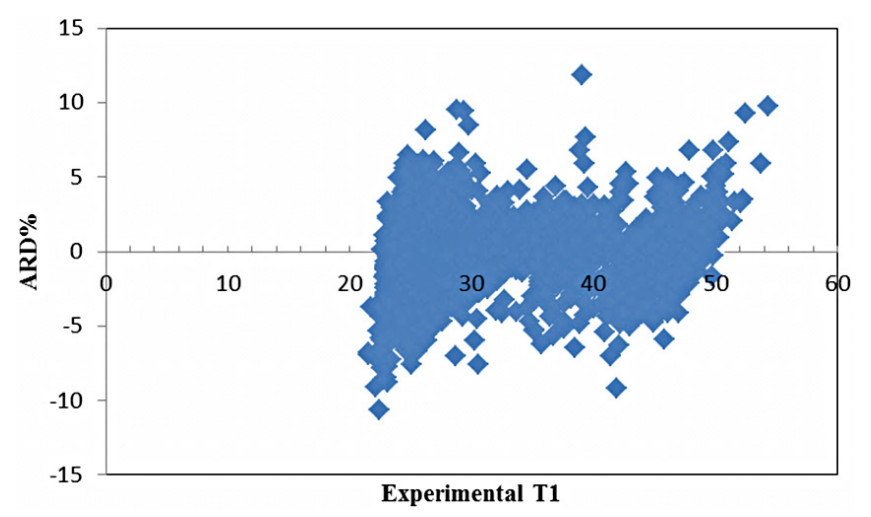

Fig. 5. Variation of relative error against the corresponding experimental $T_{1}$ values.

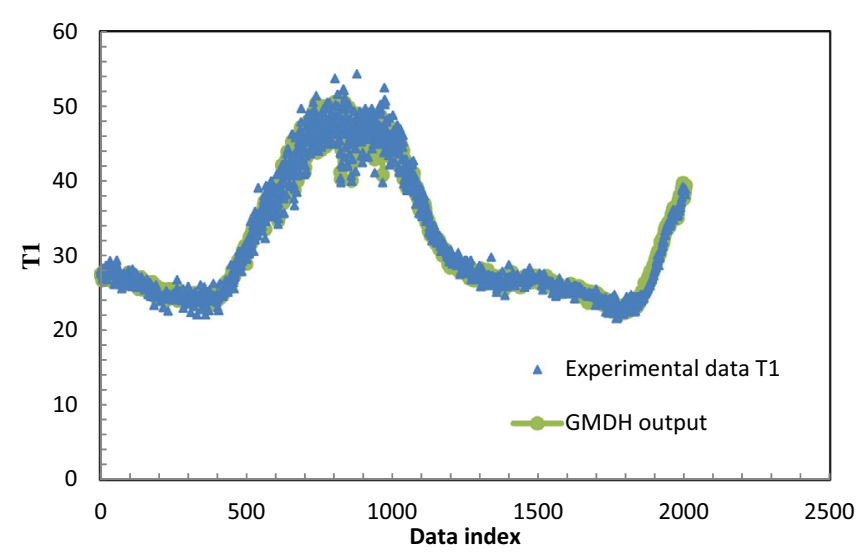

Fig. 6. Comparison between the experimental $T_{1}$ and the outcomes of the GMDH approach.

\section{Conclusions}

Efforts have been done in this research study to propose and develop an intelligent based approach to figure out the outlet temperatures of a constructed solar chimney. To gain this goal, the GMDH method was utilized to develop high predictive tool for determining the addressed variables in fast and high precised way. In addition, high accurate actual data banks were faced to the addressed predictive tool for testing and optimizing the phases. Based on the indicated statistical criteria of the output results of the developed GMDH model, the evolved method has high level of robustness and integrity for outlet temperatures of the constructed solar chimney

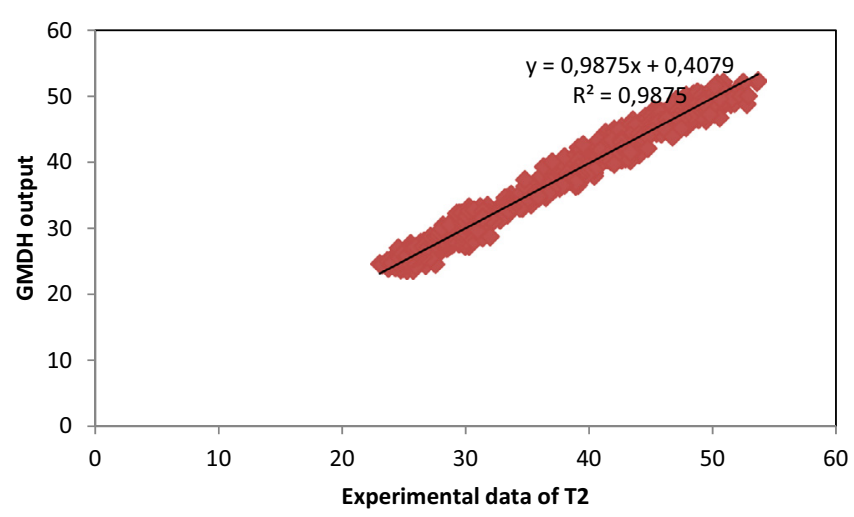

Fig. 7. Regression plot of the outputs of the developed model versus the relevant experimental $T_{2}$ data.

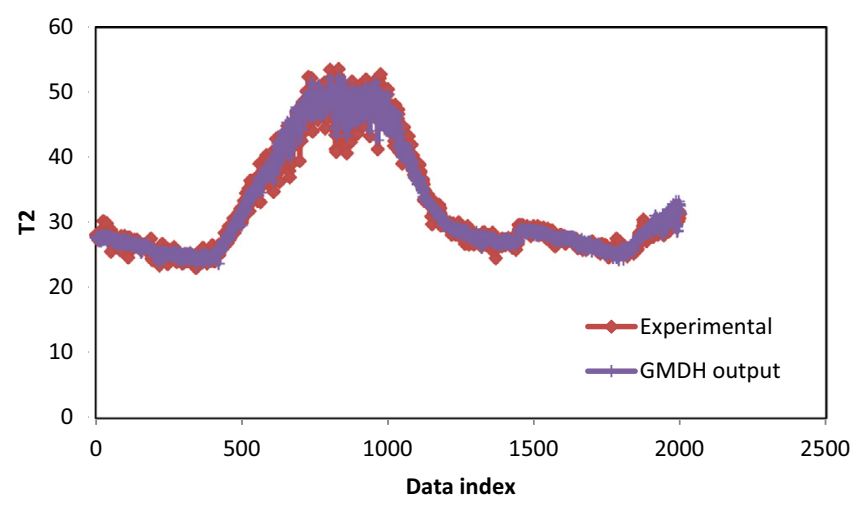

Fig. 8. Comparison between the experimental $T_{2}$ and the outputs of the GMDH approach.

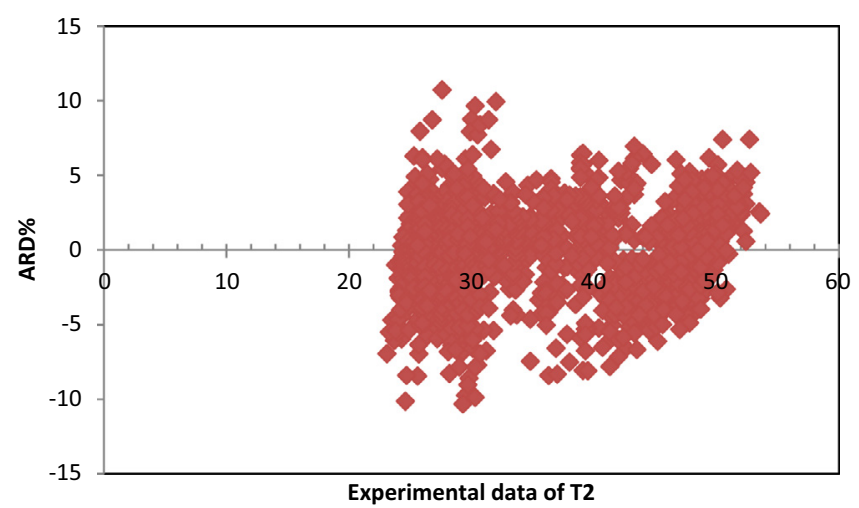

Fig. 9. Variation of relative error against the corresponding experimental $T_{2}$ values. 


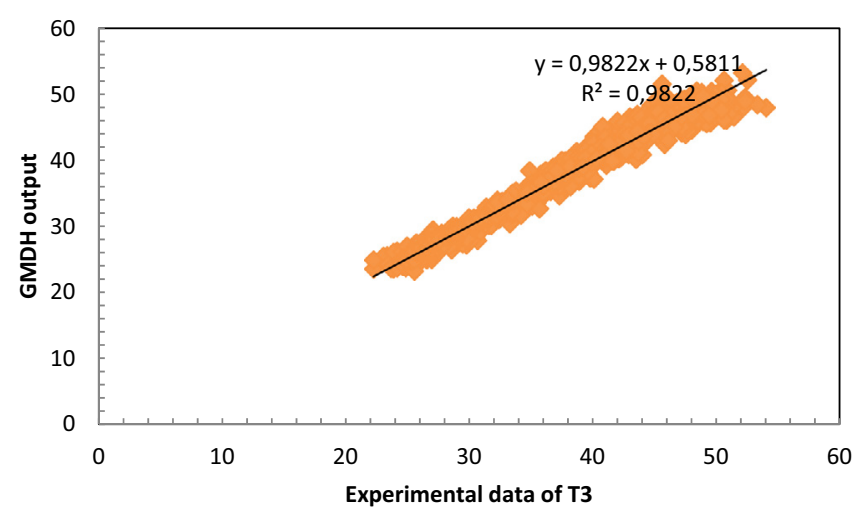

Fig. 10. Regression plot of the outputs of the developed model versus the relevant experimental $T_{3}$ data.

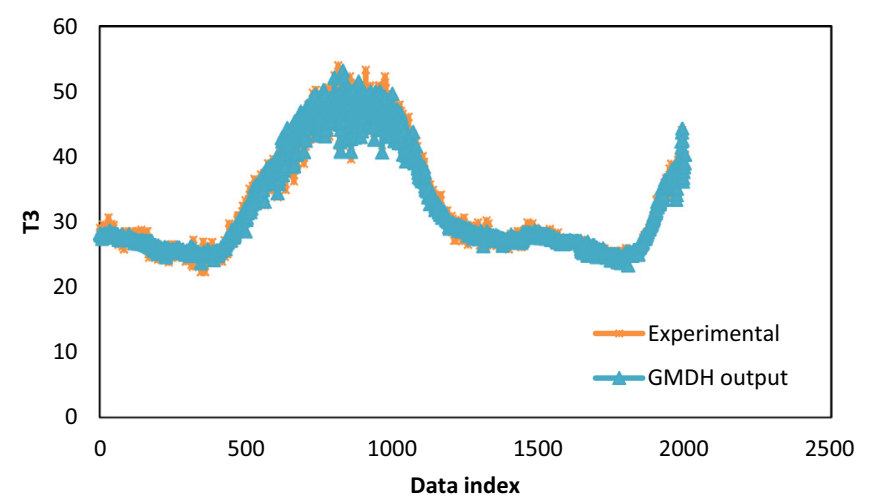

Fig. 11. Comparison between the experimental $T_{3}$ and the outcomes of the GMDH approach.

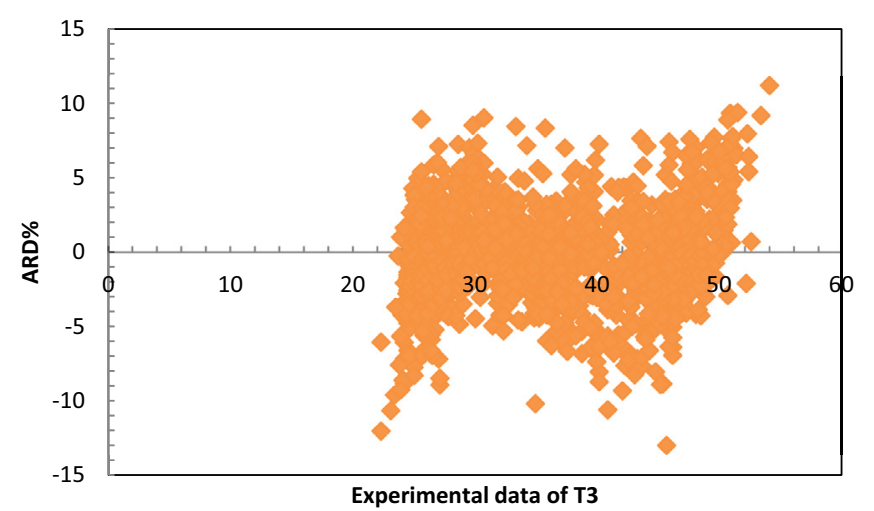

Fig. 12. Variation of relative error against the corresponding experimental $T_{3}$ values.

determination. The last step of this study is shown that the output results of the GMDH approach could help energy experts to design solar chimney with high level of performance, reliability and robustness and low degree of uncertainty. The results show that the solar chimney's experimental data were qualified and according to modeling, the formulas of the outlet temperatures have been obtained.

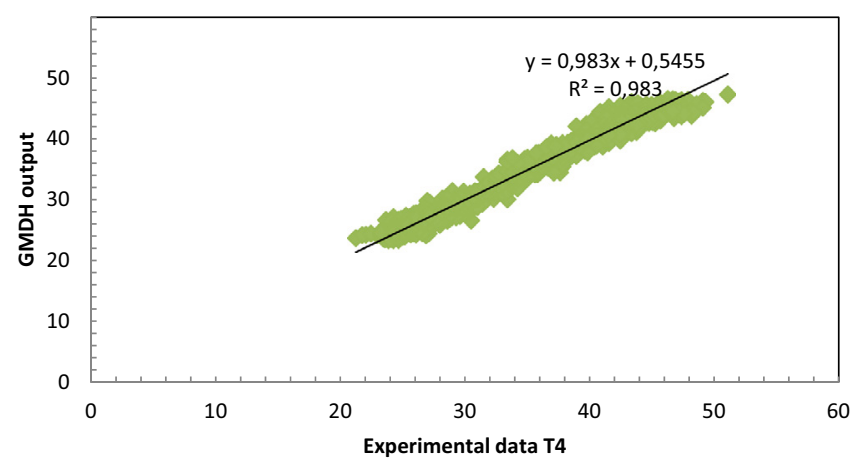

Fig. 13. Regression plot of the outputs of the developed model versus the relevant experimental $T_{4}$ data.

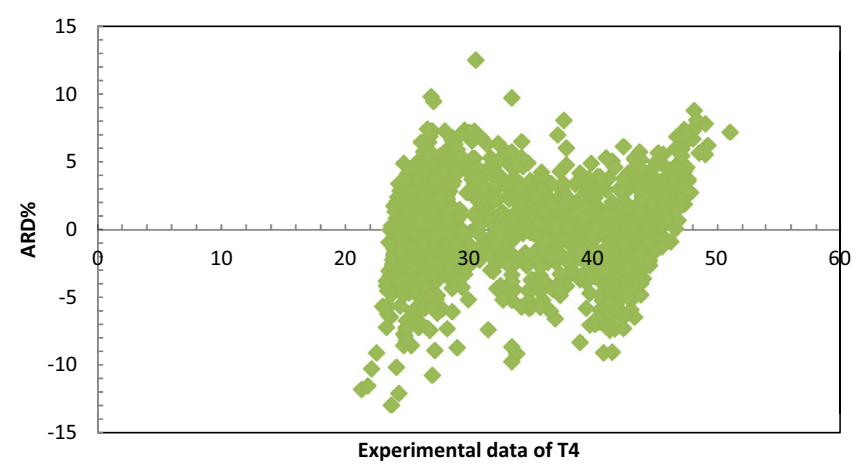

Fig. 14. Variation of relative error against the corresponding experimental $T_{4}$ values.

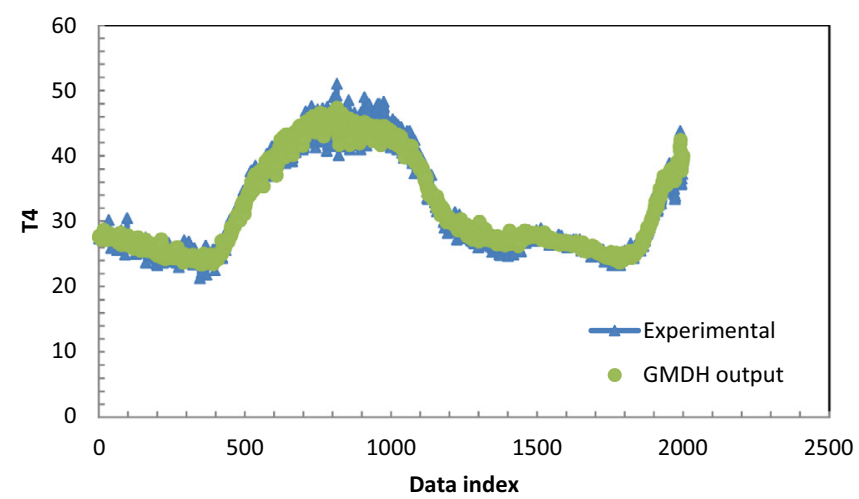

Fig. 15. Comparison between the experimental $T_{4}$ and the outputs of the GMDH approac.

\section{References}

[1] W. Haaf, K. Friedrich, G. Mayr, J. Schlaich, Solar chimneys, part I: principle and construction of the pilot plant in Manzanares, Int. J. Solar Energy 2 (1983) 3-20

[2] W. Haaf, Solar chimneys, part II: preliminary test results from the Manzanares pilot plant, Int. J. Solar Energy 2 (1984) 141-161

[3] J. Schlaich, The Solar Chimney, Electricity from the Sun, Deutsche Verlags-Anstalt, Stuttgart, 1994

[4] A.J. Gannon, T.W. Von Backstrom, Controlling and maximizing solar chimney power output, In: Proceedings of the 1st International Conference on Heat Transfer, 
Fluid Mechanics and Thermodynamics, Kruger Park, South Africa, 2002

[5] T.P. Fluri, T.W. Von Backstrom, Comparison of modelling approaches and layouts for solar chimney turbines, Solar Energy 82 (2008) 239-246

[6] M.A. Bernardes, D.S. Voß, G. Weinrebe, Thermal and technical analyses of solar chimneys, Solar Energy 75 (2003) 511-524

[7] E. Bilgen, J. Rheault, Solar chimney power plants for high latitudes, Solar Energy 79 (2005) 449-458

[8] J.P. Pretorius, D.G. Kroger, Critical evaluation of solar chimney power plant performance, Solar Energy 80 (2006) 535-544

[9] A. Koonsrisuk, T. Chitsomboon, Dynamic similarity in solar chimney modeling, Solar Energy 81 (2007) 14391446

[10] A. Koonsrisuk, T. Chitsomboon, A single dimensionless variable for solar chimney power plant modeling, Solar Energy 83 (2009) 2136-2143

[11] X. Zhou, J. Yang, B. Xiao, G. Hou, Experimental study of temperature field in a solar chimney power setup, Appl. Thermal Eng. 27 (2007) 2044-2050

[12] T.P. Fluri, J.P. Pretorius, C. Van Dyk, T.W. Von Backstrom, D.G. Kroger, G. Van Zijl, Cost analysis of solar chimney power plants, Solar Energy 83 (2009) 246256

[13] R. Petela, Thermodynamic study of a simplified model of the solar chimney power plant, Solar Energy 83 (2009) 94-107

[14] X. Zhou, J. Yang, B. Xiao, G. Hou, F. Xing, Analysis of chimney height for solar chimney power plant, Appl. Thermal Eng. 29 (2009) 178-185

[15] A. Koonsrisuk, S. Lorente, A. Bejan, Constructal solar chimney configuration, Int. J. Heat Mass Transfer 53 (2010) 327-333

[16] M. Bernardes, W. Theodor, T.W. Von Backstrom, Evaluation of operational control strategies applicable to solar chimney power plants, Solar Energy 84 (2010) 277288

[17] T. Chergui, S. Larbi, A. Bouhdjar, Thermohydrodynamic aspect analysis of flows in solar chimney power plants-A case study, Renew. Sustain. Energy Rev. 14 (2010) 1410-1418

[18] G. Xu, T. Ming, Y. Pan, F. Meng, C. Zhou, Numerical analysis on the performance of solar chimney power plant system, Energy Convers. Manage. 52 (2011) 876-883

[19] J.K. Afriyie, M.A. Nazha, H. Rajakaruna, F.K. Forson, Experimental investigations of a chimney-dependent solar crop dryer, Renew. Energy 34 (2009) 217-222

[20] J.K. Afriyie, H. Rajakaruna, M.A. Nazha, F.K. Forson, Simulation and optimization of the ventilation in a chimney-dependent solar crop dryer, Solar Energy 85 (2011) 1560-1573

[21] F. Cao, L. Zhao, L. Guo, Simulation of a sloped solar chimney power plant in Lanzhou, Energy Convers. Manage. 52 (2011) 2360-2366

[22] A. Koonsrisuk, Mathematical modeling of sloped solar chimney power plants, Energy 47 (2012) 582-589

[23] F. Cao, L. Zhao, H. Li, L. Guo, Performance analysis of conventional and sloped solar chimney power plants in China, Appl. Thermal Eng. 50 (2013) 582-592

[24] L. Zuo, Y. Zheng, Z. Li, Y. Sha, Solar chimneys integrated with sea water desalination, Desalination 276 (2011) 207213
[25] J. Li, P. Guo, Y. Wang, Effects of collector radius and chimney height on power output of a solar chimney power plant with turbines, Renew. Energy 47 (2012) 2128

[26] M. Hamdan, Analysis of solar chimney power plant utilizing chimney discrete model, Renew. Energy 56 (2013) $50-54$

[27] E. Sanchez, T. Shibata, L.A. Zadeh, Genetic algorithms and fuzzy logic systems, World Scientific, River edge NJ, 1997

[28] K. Kristinson, G. Dumont, System identification and control using genetic algorithms, J. IEEE Trans. Syst. Man. Cybern 22 (1992) 1033-46

[29] J. Koza, Genetic programming, on the programming of computers by means of natural selection, MIT Press, MA, Cambridge, 1992

[30] H. Iba, T. Kuita, deH. Garis, T. Sator, System identification using structured genetic algorithms, In: Proceedings of the 5 th international conference on genetic algorithms, ICGA'93, USA, 1993

[31] K. Rodríguez-Vázquez, Multi-objective evolutionary algorithms in non-linear system identification, Ph.D. Thesis, University of Sheffield, Sheffield, UK, 1999

[32] A.G. Ivakhnenko, Polynomial Theory of Complex Systems, IEEE Trans. Syst. Man Cybern SMC-1 (1971) 364-378

[33] S.J. Farlow, Self-organizing method in modelling, GMDH type algorithm, Marcel Dekker Inc., 1984

[34] J.A. Mueller, F. Lemke, Self-organizing data mining: an intelligent approach to extract knowledge from data, Pub. Libri, Hamburg, 2000

[35] N. Nariman-zadeh, A. Darvizeh, M.E. Felezi, H. Gharababei, Polynomial modeling of explosive compaction process of metallic powders using GMDH-type neural networks and singular value decomposition, J. Model Simul. Mater. Eng. 10 (2002) 727-44

[36] C.M. Fonseca, P.J. Fleming, Nonlinear system identification with multi-objective genetic algorithm proceedings of the 13th World congress of the international federation of automatic control, Pergamon Press, San Francisco, California, 1996, pp. 187-92

[37] G.P. Liu, V. Kadirkamanathan, Multi-objective criteria for neural network structure selection and identification of nonlinear systems using genetic algorithms, IEEE Proc. Control Theory Appl. 146 (1999) 373-82

[38] N. Nariman-Zadeh, A. Darvizeh, R. Ahmad-Zadeh, Hybrid Genetic Design of GMDH-Type Neural Networks Using Singular Value Decomposition for Modelling and Prediction of the Explosive Cutting Process, Proc. I MECH E Part B. J. Eng Manuf. 217 (2003) 779-790 
[39] V.W. Porto, Evolutionary computation approaches to solving problems in neural computation, In: Handbook of evolutionary computation, edited by Back D.B. Fogel, Michalewicz Z, Oxford University Press, Institute of Physics Publishing and New York, 1997, pp. D1.2, 1-6

[40] X. Yao, Evolving artificial neural networks, Proc. IEEE 87 (1999) 1423-47

[41] E.F. Vasechkina, V.D. Yarin, Evolving polynomial neural network by means of genetic algorithm: some application examples, Complex Int. 9 (2001)

[42] X. Yao, Evolving Artificial Neural Networks, Proc. IEEE 87 (1999) 1423-1447

[43] N. Nariman-zadeh, K. Atashkari, A. Jamali, A. Pilechi, $\mathrm{X}$. Yao, Inverse modelling of multi-objective thermodynamically optimized turbojet engines using GMDH-type neural networks and evolutionary algorithms, J. Eng. Optim. 37 (2005) 43-62

[44] B.R. Munson, D.F. Young, T.O. Okiishi, Fundamentals of fluid mechanics, 2nd edition, John Wiley \& Sons, Inc, 1994, Chap. 2

[45] J. Schlaich, R. Bergermann, W. Schiel, G. Weinrebe, Design of commercial solar updraft tower systems utilization of solar induced convective flows for power generation, J. Solar Energy Eng. 127 (2005) 117-124

[46] K. Atashkari, Nariman-Zadeh, N, Jamali, A, Pilechi, A, Thermodynamic Pareto optimization of turbojet using multi-objective genetic algorithm, Int. J. Thermal Sci. 44 (2005) 1061-1071
[47] K. Atashkari, N. Nariman-Zadeh, M. Golcu, A. Khalkhali, A. Jamali, Modelling and multi-objective optimization of a variable valve-timing spark- ignition engine using polynomial neural networks and evolutionary algorithms, Energy Convers. Manage. 48 (2007) 1029-1041

[48] A. Jamali, N. Nariman-zadeh, A. Darvizeh, A. Masoumi, S. Hamrang, Multi- objective evolutionary optimization of polynomial neural networks for model- ling and prediction of explosive cutting process, Eng. Appl. Artif. Intell. 22 (2009) 67-687

[49] J.I.E. Lin, C.T. Cheng, K.W. Chau, Using support vector machines for long-term discharge prediction, Hydrolo. Sci. J. 51 (2006) 599-612

[50] M.H. Ahmadi, M.-A. Ahmadi, M. Mehrpooya, M.A. Rosen, Using GMDH Neural Networks to Model the Power and Torque of a Stirling Engine, Sustainability 7 (2015) 2243-2255

[51] R. Shirmohammadi, B. Ghorbani, M. Hamedi, M.-H. Hamedi, L.M. Romeo, Optimization of mixed refrigerant systems in low temperature applications by means of group method of data handling (GMDH), J. Natural Gas Sci. Eng. 26 (2015) 303-312

[52] S.M. Pourkiaei, H.A. Mohammad, S. Mahmoud Hasheminejad, Modeling and experimental verification of a $25 \mathrm{~W}$ fabricated PEM fuel cell by parametric and GMDH-type neural network, Mech. Ind. 17 (2016) 105 